\title{
Study of Subsonic input Device, Integrated with Aircraft Forebody
}

\author{
Postnikov A.A. ${ }^{1}$, Vinogradov V.A. ${ }^{1}$, Komratov D.V. ${ }^{1}$, Stepanov V.A. ${ }^{1}$, \\ Skryabin A.S. ${ }^{2}$ \\ ${ }^{1}$ Central Institute of Aviation Motors, \\ Moscow, 111116, Russia \\ ${ }^{2}$ Bauman Moscow State Technical University, \\ Moscow, 105005, Russia \\ Postaa@rambler.ru
}

\begin{abstract}
This paper presents the results of numerical and experimental study of subsonic intake, integrated with curvilinear fuselage fore body under subsonic flowing. Numerical research of air intake flow and performance were obtained at different throttle modes and turbulence models at flight altitude $H=0 \div 0.5 \mathrm{~km}$ and Mach number $\mathrm{M}=0.4$. An experimental research was performed in wind tunnel of Central Institute of Aviation Motors at $\mathrm{M}=0.4$, an attack angle $\alpha=0^{\circ}$ and Reynolds number $\operatorname{Re}=1.8 \times 10^{6}$. The losses of total pressure at the different throttle modes, distribution of the static pressure along the intake and fuselage length were determined. Satisfactory agreement between calculated and experimental data was obtained. A flow control air intake methods are proposed.
\end{abstract}

Keywords: curvilinear fuselage, numerical-experimental research at subsonic speeds, throttle performance. 


\title{
Исследование процессов обтекания дозвукового входного устройства, интегрированного с планером летательного аппарата
}

\author{
Постников А.А. ${ }^{1}$, Виноградов В.А. ${ }^{1}$, Комратов Д.В. ${ }^{1}$, Степанов В.А. \\ Скрябин А.C. ${ }^{2}$ \\ ${ }^{1}$ Центральный институт авиациионного моторостроения, \\ Россия, Москва, 111116, ул. Авиамоторная, 2 \\ ${ }^{2}$ Московский государственный технический университет им. Н.Э. Баумана, \\ Россия, Москва, 105005, 2-я Бауманская ул., д. 5, стр. 1 \\ Postaa@rambler.ru
}

\begin{abstract}
Аннотация
Рассмотрены результаты численного и экспериментального исследования особенностей обтекания дозвуковым воздушным потоком воздухозаборника в интеграции с планером ЛА с криволинейным фюзеляжем. С помощью численного моделирования, основанного на решении трехмерных уравнений Навье-Стокса, получены результаты обтекания воздухозаборника на разных дроссельных режимах работы при $\mathrm{M}_{0}=0.4$ и высоте полета $H=0 \div 0.5$ км. с разными моделями турбулентности. Экспериментальное исследование выполнено на модели в аэродинамической трубе ЦИАМ с набегающим потоком $\mathrm{M}_{0}=0.4$ при угле атаки $\alpha=0^{\circ}$ и числе Рейнольдса $\operatorname{Re}=1.8 \times 10^{6}$. Определены потери полного давления на разных дроссельных режимах и распределения статического давления по длине канала воздухозаборника и по длине фюзеляжа. Получено удовлетворительное соответствие расчетных и экспериментальных данных. Рассмотрены особенности течения в воздухозаборнике и получены режимы обтекания с минимальными потерями полного давления.
\end{abstract}

Ключевые слова: криволинейный фюзеляж, расчетно-экспериментальное исследование при дозвуковых скоростях, дроссельные характеристики

\section{1. Введение}

Исследования воздухозаборников для дозвуковых гражданских самолетов всегда являлось актуальной задачей, так как повышение требований к тягово-экономическим характеристикам и экологичности силовых установок зависит от газодинамической эффективности входных устройств (ВУ). В зависимости от требований к условиям полета расположение входных устройств на ЛА может быть различным. Довольно распространенным случаем компоновки является интеграция воздухозаборника (В3) с фюзеляжем летательного аппарата. Примером может служить коммерческий маломестный гражданский самолет [1]. Компоновка этого летательного аппарат включает в себя интеграцию D-образного входного устройства, расположенного в хвостовой части на клине слива. Такая компоновка обусловлена требованиями обеспечения необходимых режимов полета ЛА. В то же время, это может приводить к попаданию пограничного слоя во входное устройство и, как следствие, увеличивать неравномерности течения в самом В3 и на выходе из него.

В настоящей работе рассматривается установка дозвукового воздухозаборного устройства в тени за носовой частью фюзеляжа летательного аппарата. В этом случае параметры потока перед входом в В3 в значительной степени определяются геометрией фюзеляжа. 
Целью настоящей работы является численное и экспериментальное исследование влияния криволинейного фюзеляжа на аэродинамические характеристики входного устройства ЛА, предназначенного для полетов с крейсерской скоростью $\mathrm{M}=0.4$.

Задачами в рамках поставленной цели являются:

- $\quad$ проектирование, изготовление и проведение стендовых испытаний модельного входного устройства (ВУ) с моделированием крейсерского режима полета $\mathrm{M}=0.4$ для определения эффективности торможения в ВУ;

- расчет и анализ локальных и интегральных характеристик течения в ВУ на режимах, моделирующих условия свободного обтекания ВУ, интегрированного с криволинейным фюзеляжем при $H=0 \div 0.5$ км с крейсерской скоростью полета, соответствующей $\mathrm{M}=0.4$;

- сравнение данных экспериментального исследования с результатами численного анализа с использованием различных моделей турбулентности.

\section{2. Методика эксперимента}

Экспериментальные исследования проводились в аэродинамической трубе (АДТ) УВ16 ЦИАМ при моделировании следующих требований к условиям испытаний и конструктивных особенностей модели ВУ:

- $\quad$ крейсерский полет при $\mathrm{M}=0.4$ на высоте $H=0 \div 0.5$ км;

- $\quad$ углы атаки и скольжения, набегающего на В3 потока, равны нулю;

- $\quad$ режимы дросселирования задаются стендовым дроссельным устройством, установленным в канале за В3;

- $\quad$ испытываемая модель объекта включает фюзеляж и воздухозаборник фиксированной геометрии, установленный на клине в теневой области за фюзеляжем ЛА, как показано на рис. 1 ;

- для уменьшения доли захватываемого пограничного слоя, образующегося на фюзеляже, воздухозаборник устанавливается на пилоне фиксированной высоты, равной 1.5 мм;

- $\quad$ выходной диаметр модели В3 составляет 50 мм, длина модели 400 мм (рис. 1);

- $\quad$ В3 установлен по оси АДТ.

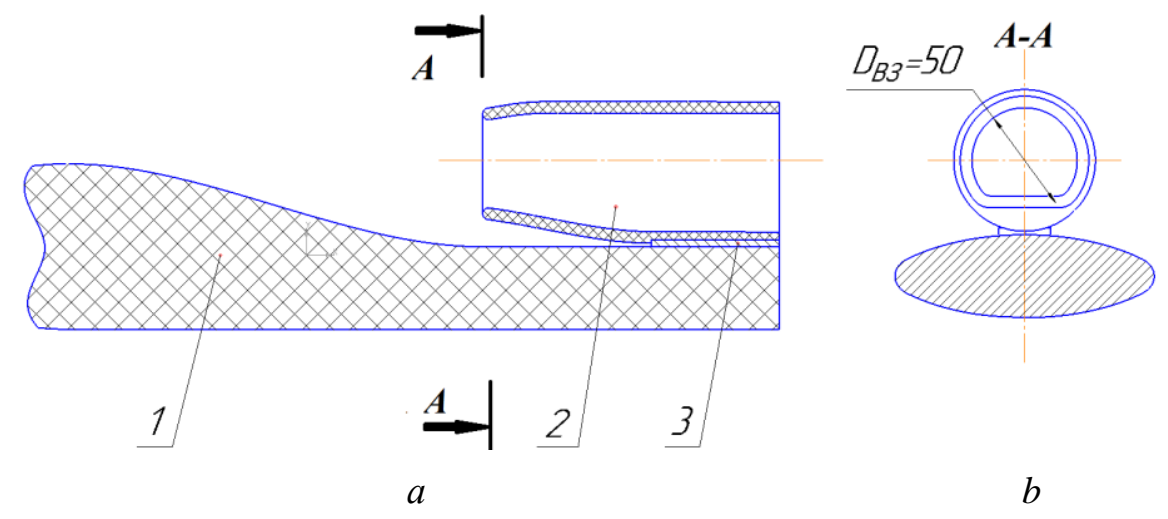

Рис. 1. Принципиальная схема испытываемой модели: $a$ - виду сбоку; $b$ - вид спереди в разрезе; 1 - фюзеляж ЛА; 2 - воздухозаборник; 3 - клин слива

Воздухозаборник (2) крепится к фюзеляжу ЛА (1) эллиптического сечения с установкой на клин слива (3), как показано на схеме рис. 1, $a$. Такая конструкция фюзеляжа позволяет уменьшить вертикальный размер исследуемой модели. Воздухозаборник выполнен с деформированной губой в нижней части его входа, что позволяет перепустить пограничный слой, образовавшийся на фюзеляже, и улучшить качество забираемого входного потока. Высота клина слива (3) может быть изменена дополнительными сменными пластинами для увеличения или уменьшения расстояния между входным устройством и фюзеляжем. 
В соответствии с выбранной концепцией исследуемого объекта (см. рис. 1) была спроектирована и изготовлена модель для экспериментальных исследований в аэродинамической трубе непрерывного действия УВ-16 ЦИАМ с размерами сечения рабочей части $250 \times 250$ мм $^{2}$. Компьютерное изображение модели В3, установленного в рабочей части трубы, представлен на рис. 2. Модель крепится к дроссель-расходомерному устройству (7) в рабочей части АДТ с расширительными нишами и решеткой (4) для моделирования условий обтекания в свободном потоке и минимизации влияния стенок на получаемые характеристики. Результаты исследования модернизации тракта введением ниш и решетки представлены в [2]. Равномерность набегающего потока (1) обеспечивается за счет лемнискатного входа в тракт АДТ. Испытываемая модель включает фюзеляж (3), воздухозаборник (5) и измерительную секцию (6), в которой располагаются гребенки приемников полного давления.
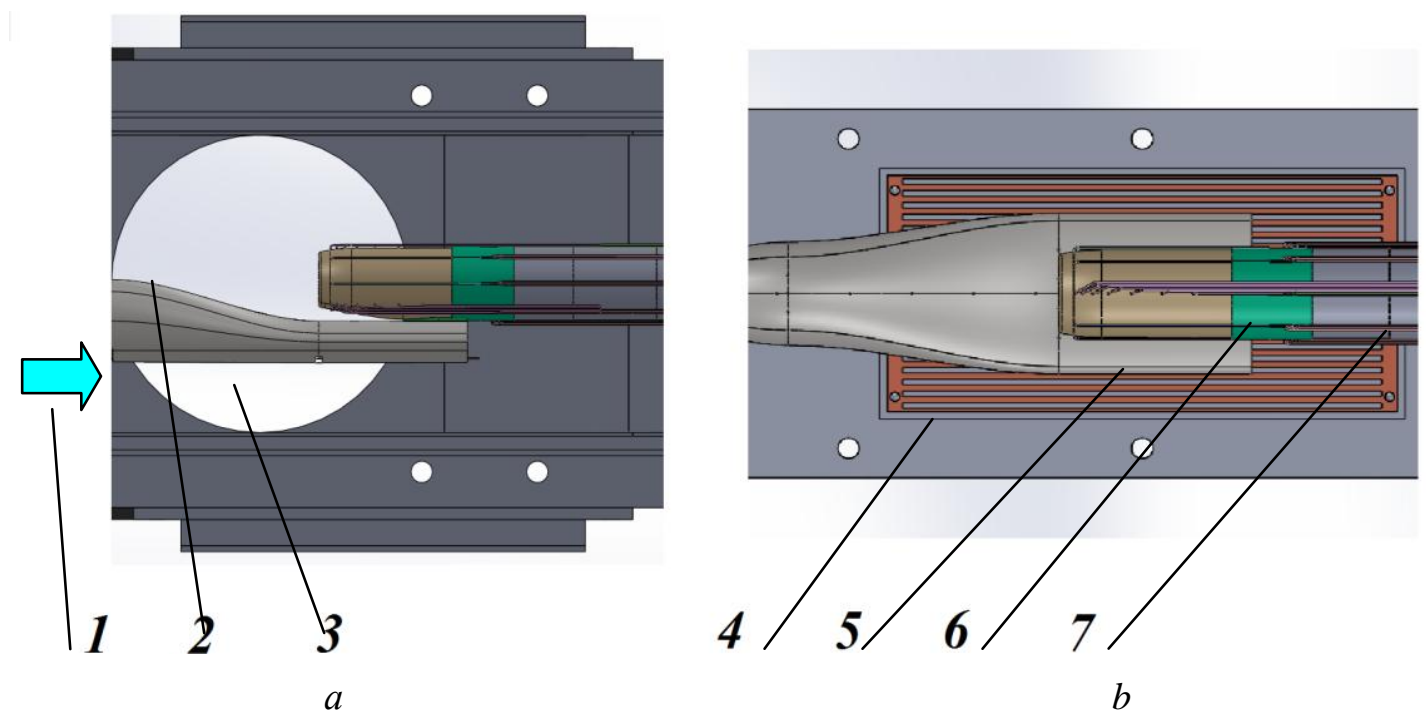

Рис. 2. Схема установки модели воздухозаборника в рабочей части аэродинамической трубы УВ-16: $a, b$ - вид сбоку и сверху; 1 - набегающий поток; 2 - окна-иллюминаторы с оптическими стеклами; 3 - фюзеляж ЛА; 4 - ниши для расширения рабочей части; 5 - воздухозаборник; 6 - измерительная секция; 7 - магистраль дроссель - расходомерного устройства

Экспериментальная модель - фюзеляж и В3 изготавливались с использованием аддитивных технологий (рис. 3). Значения чисел Рейнольдса, рассчитанные по параметрам набегающего потока с $\mathrm{M}=0.4$ и длине фюзеляжа до сечения входа в B3, равной 250 мм, составляли $\operatorname{Re}=1.8 \times 10^{6}$. Таким образом, на фюзеляже вблизи входа в B3, характеристики образующегося пограничного слоя были близки к турбулентному. Загромождение сечения трубы составляет $20 \%$.

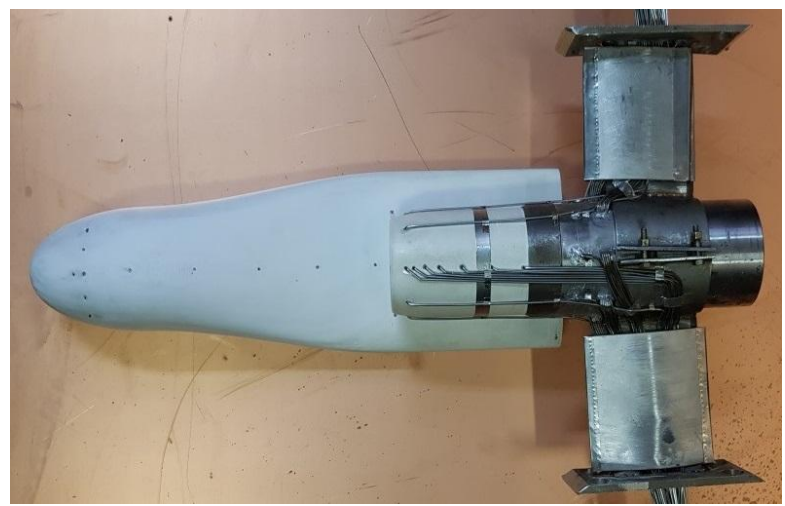

$a$

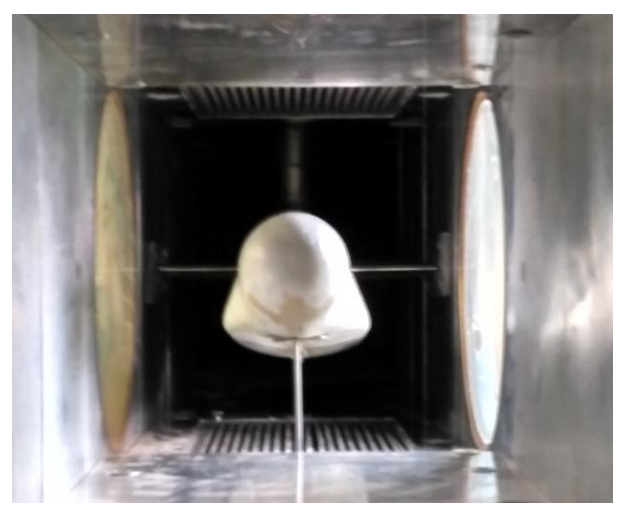

$b$

Рис. 3. Фотографии исследованной модели: $a$ ) вид сверху; $b$ ) модель в АДТ УВ-16 
В процессе испытаний В3 измерялись:

1) распределения статического давления:

- по длине фюзеляжа в плоскости симметрии (7 точек);

- по круговой образующей фюзеляжа в сечении входа в В3 (4 точки);

- в канале В3 по образующим, соответствующим лучам гребенки, установленной в выходном сечении (всего 20 точек);

- по кольцевой образующей вблизи выхода из В3 в плоскости приемников полного давления (8 точек через $\left.45^{0}\right)$;

2) полное давление вблизи выхода из В3 с помощью восьмилучевой гребенки насадков

Пито (52 насадка), рис. 4;

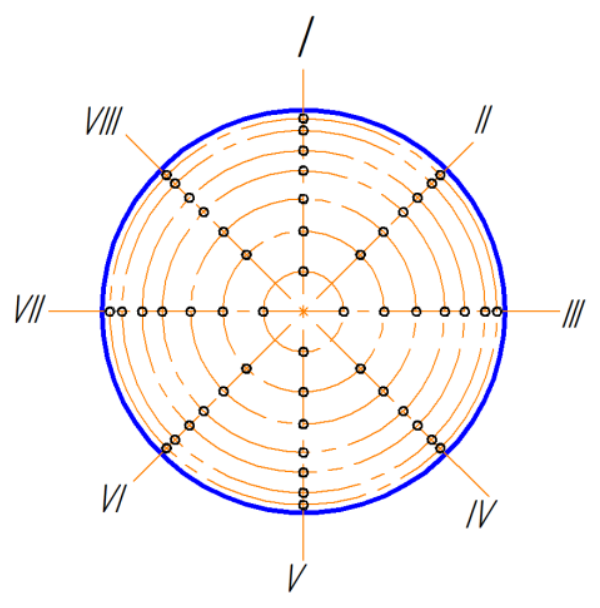

$a$

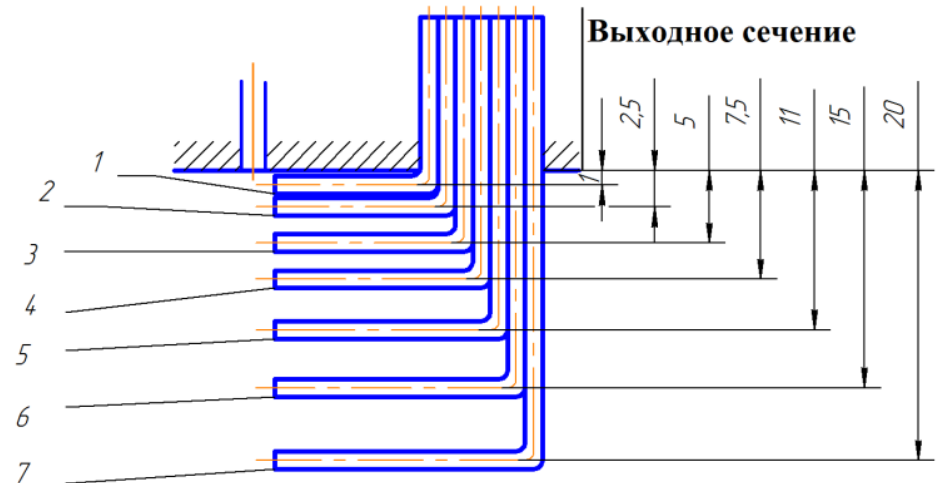

Ocb B3

$b$

Рис. 4. Схема измерения полного давления в выходном сечении воздухозаборника: $a$-расположение насадков восьмилучевой гребенки (вид спереди); $b$ - расположение насадков на луче гребенки

В процессе испытаний изменялась степень дросселирования течения, задаваемая как $P_{\text {др. }} / P^{*}$, в воздухозаборнике с помощью стендового дроссель - расходомерного устройства, установленного в магистрали за В3. Конструкция устройства при дросселировании предусматривает изменение проходного сечения окна в цилиндрическом стакане при его вращении.

Для визуализации картины обтекания через специальные отверстия (4 отв.), расположенные в поперечном сечении на расстоянии 175 мм до сечения входа В3, с поверхности фюзеляжа инжектировалась смесь краски со спиртом.

Параметры потока перед испытываемой моделью и в рабочей части трубы определя-

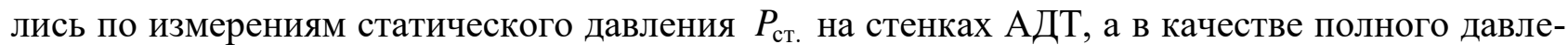
ния принималось давление на входе в АДТ, т.е. атмосферное.

По осредненным значениям $\left(P_{\text {ст. }}\right)$ средн. рассчитывалась скорость в выходном сечении В3, т.е. число Маха $\mathbf{M}_{\text {вых. }}$ Изменение $\mathbf{M}_{\text {вых. }}$ определяется в основном степенью дросселирования В3.

Для измерения давления использовались датчики абсолютного давления на разрежение «BD sensor DMP 331» с диапазоном измерения 1 Бар и относительной погрешностью \pm 0.25 \% от диапазона измерения. Измерительный сигнал передавался на 16-разрядное АЦП NI 6225 с максимальной частотой опроса 250 кГц.

Методическая погрешность обработки экспериментальных данных не превышает $3 \div 5 \%$. 


\section{3. Методика расчет обтекания ВЗ в компоновке с фюзеляжем ЛА}

Схема и геометрические размеры расчетной области (2), рис. 5, с размещенным В3 диаметра $d_{y}$ в компоновке с фюзеляжем ЛА (3), составляют 5-10 калибров $d_{y}$ вдоль соответствующих осей координат. Принятые размеры расчетной области уменьшают влияние использованных упрощенных граничных условий. Для сокращения времени счета рассмотрено обтекание модели В3 с продольной плоскостью симметрии. Для лучшего описания пристеночной области строилась неравномерная сетка с увеличением числа ячеек в пристеночной области потока около обтекаемой модели. Общее количество гексагональных ячеек в поле течения составляло $3.4 \times 10^{6}$.

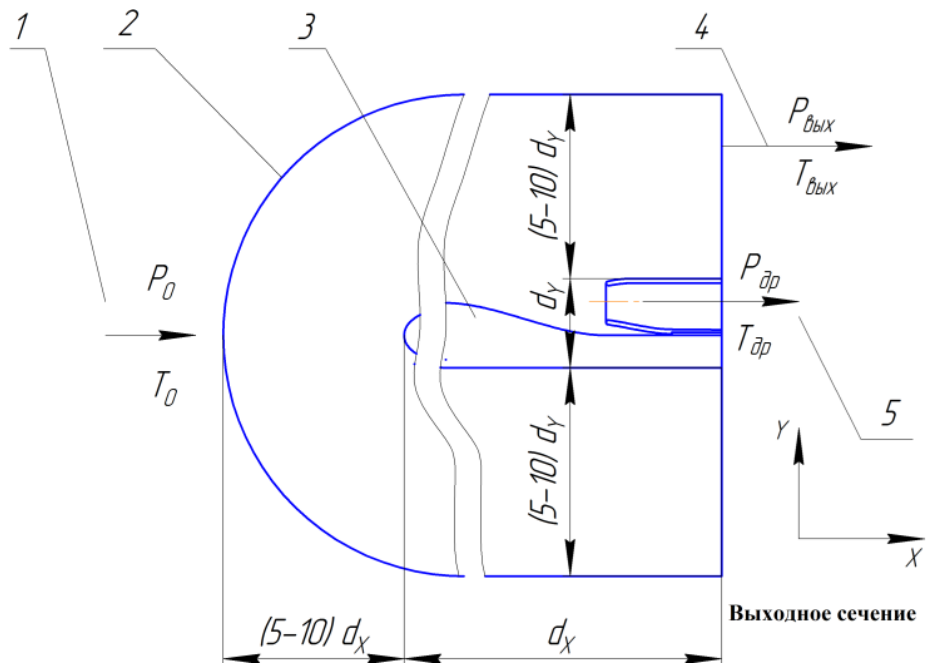

Рис. 5. Принципиальная схема расчетной области и задание граничных условий: 1 - входные параметры; 2 - границы расчетной области; 3 - исследуемая модель; 4 - выходные параметры в области внешнего обтекания; 5 - параметры на выходе из В3, задаваемые при изменении степени дросселирования

Граничные условия задавались в соответствии с параметрами исследования в АДТ. На входе в канал задавались полные параметры потока: давление $P_{0}=1 \times 10^{5}$ Па и температура

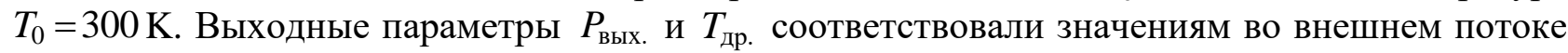
на рассматриваемом режиме полета $\left(\mathrm{M}_{0}=0.4\right)$. Условия дросселирования В3 задавались величинами $P_{\text {др. }}$ и $T_{\text {др. }}$.

Расчеты выполнялись с помощью программного комплекса ESI - Software [3], основанного на решении стационарных уравнений Навье - Стокса, осредненных по Рейнольдсу для трехмерных вязких течений. Для описания турбулентных характеристик в разных областях течения использовались двухпараметрические $k-\varepsilon$ и SST модели турбулентности. В работе [4] показано, что в аналогичных условиях модель турбулентности $k$ - $\varepsilon$ показывает достаточно хорошую корреляцию с экспериментальными данными.

Симметричная постановка выбиралась для уменьшения времени счета. Однако, для сравнения, на одном из режимов был проведен расчет с полной исследуемой моделью. Расчет показал хорошее совпадение распределений полного давления на выходе из В3 для обеих схем расчета.

\section{4. Результаты экспериментально - теоретических исследований обтекания модели}

Испытания модели показали сильную зависимость потерь полного давления $\sigma_{\mathrm{B} 3}$ от степени дросселирования $P_{\text {др. }} / P^{*}$. В частности, следует заметить, что начальное дросселирование, вызываемое загромождением гребенкой выходного сечения тракта составляет $\approx 2 \%$, что также влияло на течение и получаемые параметры. Стоит отметить наблюдавшееся не- 
симметричное относительно плоскости симметрии модели растекание краски по фюзеляжу ЛА (рис. 6) при визуализации пристеночного течения, что говорит о возможной погрешности установки модели с незначительным углом скольжения $\approx 1^{\circ}$.

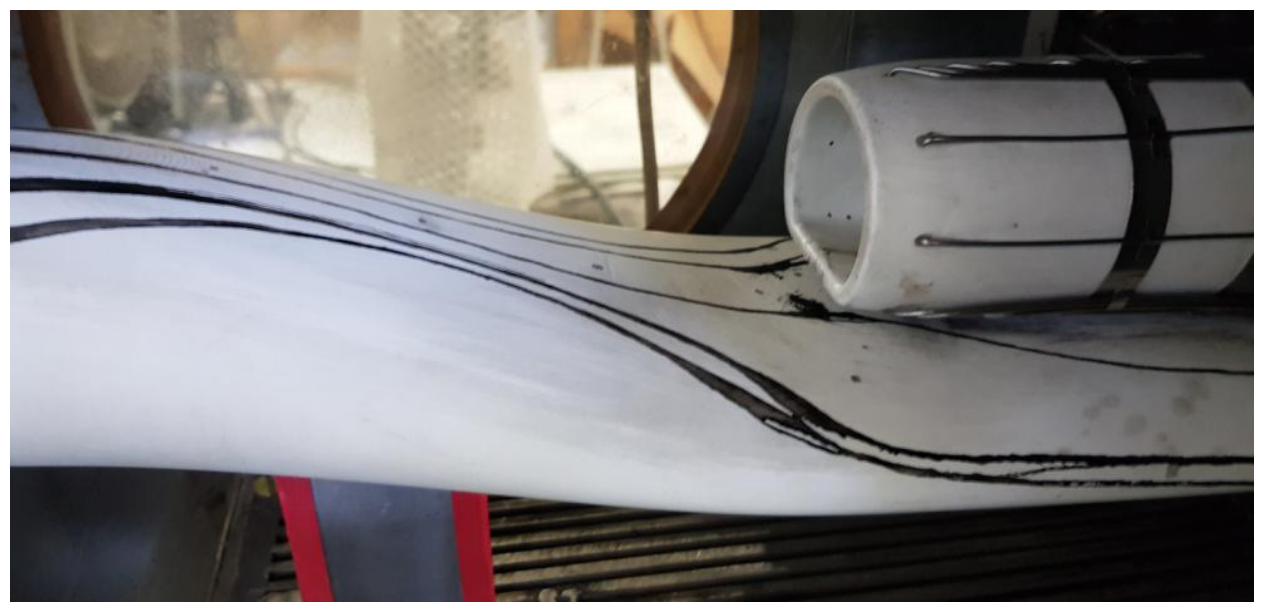

Рис. 6. Картина линий тока набегающего потока на фюзеляже исследуемой модели

Сравнительные картины расчетных и экспериментальных распределений полного давления представлены на рис. 7. Различия полей возможно вызваны отмечавшимися ранее погрешностями установки модели в тракте АДТ, тогда как в расчете принимался нулевой угол скольжения.

Поля полного давления в результате численного моделирования
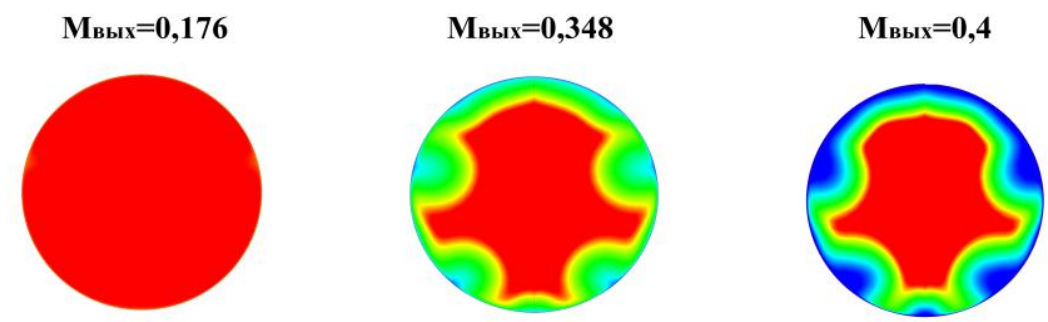

Поля полного давления в результате эксперимента
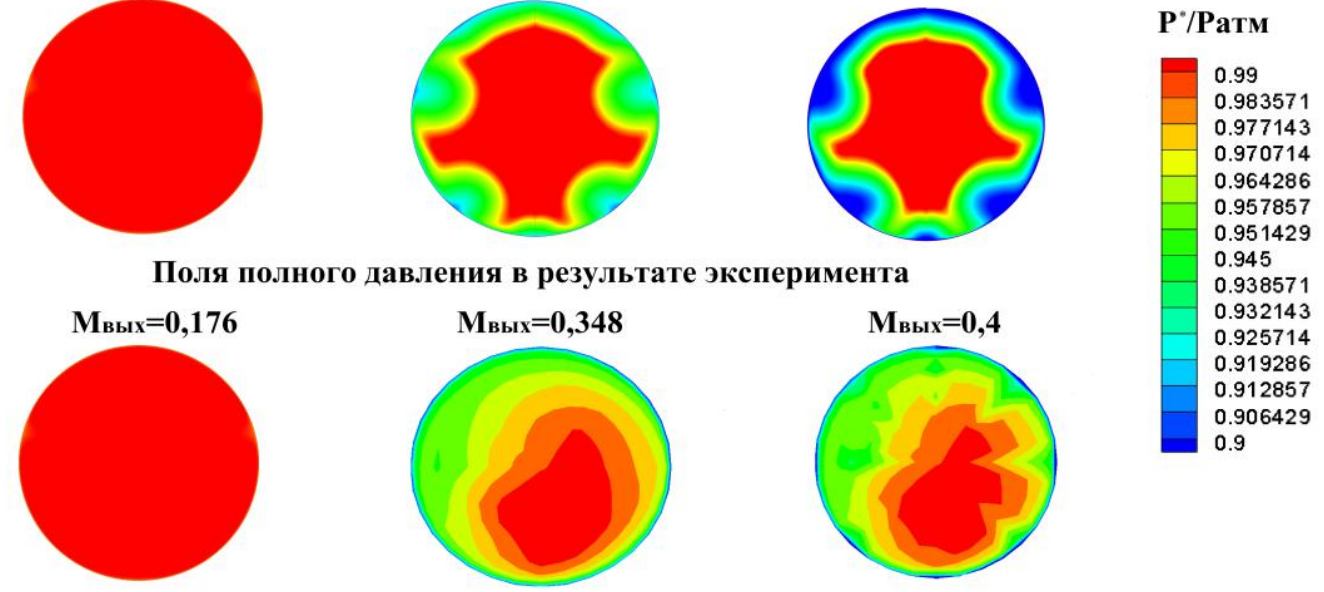

Рис. 7. Сравнительные картины полей полного давления на выходе из В3 на разных режимах дросселирования в эксперименте и численном моделировании

Значения потерь полного давления $\sigma$ определялись осреднением по выходному сечению канала В3 по формуле

$$
\sigma=\frac{1}{P *} \sum_{i=1}^{N} P_{i} * \frac{\Delta S_{i}}{S},
$$

где $P_{i}^{*}$ - значение давления, измеряемого насадком; $\Delta S_{i}$ - значение площади струйки тока для рассматриваемого насадка; $N$ - число насадков в гребенке. На рис. 8 приведены расчетные и экспериментальные значения $\sigma$, полученные для различных режимов обтекания с дросселированием $\sigma=f\left(\mathrm{M}_{\text {вых. }}\right)$. Там же приведены поля обезразмеренных полных давлений 
$\sigma=P / P_{\text {атм }}$, полученные интерполяцией давлений $P$, измеренных 8 -ми лучевой гребенкой насадков полного давления, для некоторых значений степени дросселирования.

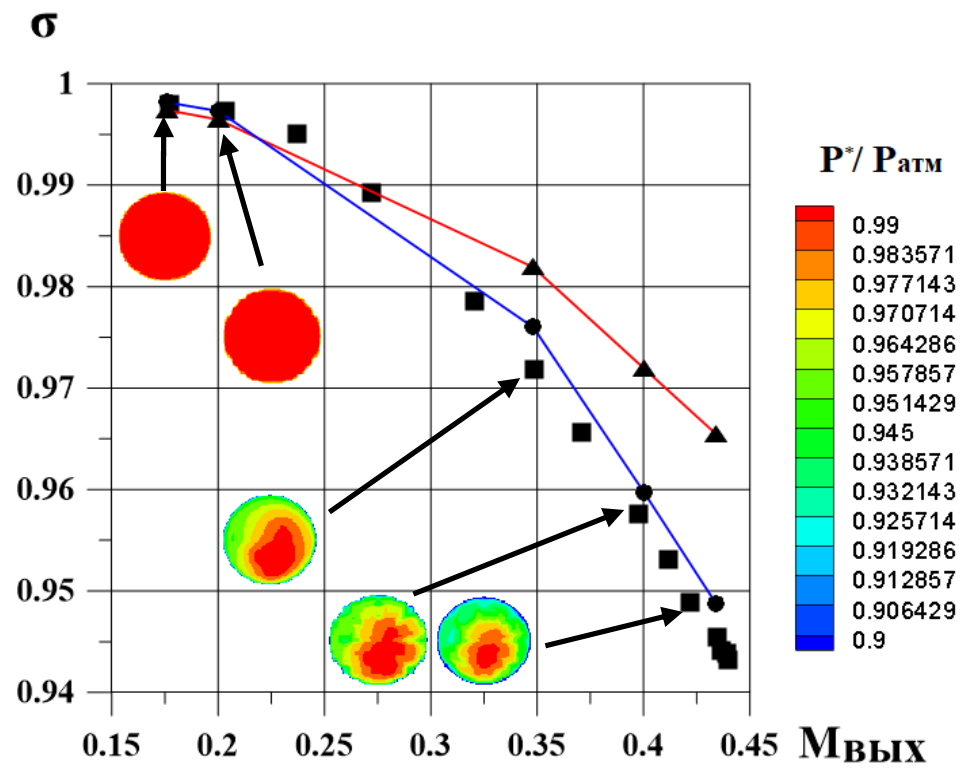

Рис. 8. Экспериментальные и расчетные зависимости потерь полного давления от чисел Маха на выходе из В3:

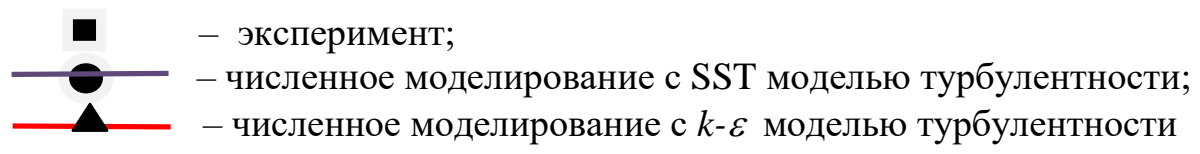

Значения безразмерного расстояния от первого узла сетки до стенки модели $Y^{+}<8$, получившиеся в задачах численного моделирования свидетельствует о достаточно хорошем описании течения в пристеночной области исследуемой модели. Результаты численного моделирования с различными моделями турбулентности показаны в виде кривых на рис. 8 . Можно отметить, что при малых выходных скоростях $\mathrm{M}_{\text {вых. }}=0.15 \div 0.25$ (на режимах с малым дросселированием) расчетные и экспериментальные данные хорошо соответствуют друг другу. С изменением степени дросселирования отличие расчетных данных с $k$ - $\varepsilon$ моделью турбулентности от данных расчета с SST моделью турбулентности и экспериментальных данных увеличивается до $(2 \div 2.2) \%$. В то же время, расчетные данные с SST моделью турбулентности хорошо коррелируют с результатами эксперимента и максимальное отличие не превышает $0.43 \%$. Отличие, полученных экспериментальных значений $\sigma\left(\mathrm{M}_{\text {вых. }}\right)$ от расчетных данных $\Delta \sigma\left(\mathrm{M}_{\text {вых. }}\right)=\left(\sigma_{\text {эксп. }}-\sigma_{\text {расч. }}\right) / \sigma_{\text {расч. }}$ приведено в табл. 1.

Таблица 1

Сравнение расчетных и экспериментальных значений $\sigma\left(\mathrm{M}_{\text {вых }}\right)$

\begin{tabular}{|l|c|c|c|c|c|}
\hline$M_{\text {вых }}$ & $\sigma_{\text {экспер. }}$ & $\begin{array}{c}\sigma_{\text {расч. }} \\
k-\varepsilon \text { модель } \\
\text { турбулентности }\end{array}$ & $\begin{array}{c}\sigma_{\text {расч. }} \\
\text { SST модель } \\
\text { турбулентности }\end{array}$ & $\sigma\left(\mathrm{M}_{\text {вых. }}\right)_{k-\varepsilon}, \%$ & $\sigma\left(\mathrm{M}_{\text {вых. }}\right)_{\mathrm{SST}}, \%$ \\
\hline 0.176 & 0.998 & 0.997 & 0.998 & 0.049 & 0.025 \\
\hline 0.2 & 0.997 & 0.997 & 0.997 & 0.082 & 0.001 \\
\hline 0.348 & 0.972 & 0.982 & 0.976 & 1.041 & 0.429 \\
\hline 0.4 & 0.958 & 0.972 & 0.959 & 1.500 & 0.221 \\
\hline 0.434 & 0.945 & 0.965 & 0.948 & 2.125 & 0.351 \\
\hline
\end{tabular}

С изменением степени дросселирования, т.е. с увеличением от $\mathrm{M}_{\text {вых. }}=0.176$ до $\mathrm{M}_{\text {вых. }}=0.45$, потери полного давления в выходном сечении В3 увеличиваются на $\approx 5 \%$, что 
показано на рис. 8. Стоит отметить, что картина полей полного давления значительно изменяется уже на режиме дросселирования, соответствующем $\mathrm{M}_{\text {вых. }}=0.348$. Сравнительные картины численного моделирования обтекания фюзеляжа и B3 с SST моделью турбулентности представлены на рис. 9.
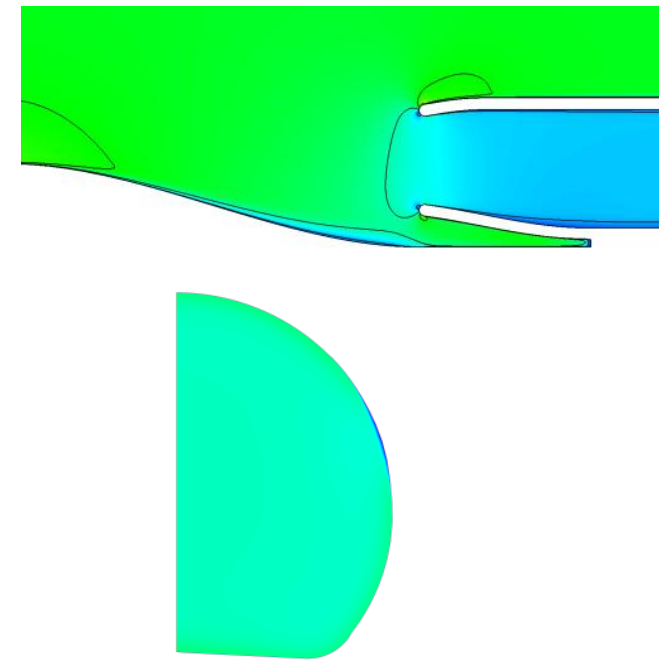

$a$
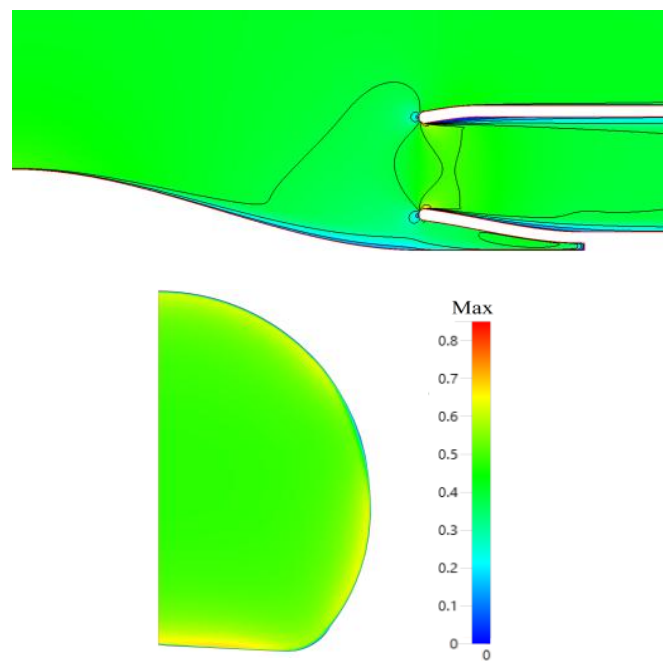

$b$

Рис. 9. Продольное и поперечное сечение обтекания исследуемой модели на входе в В3 с SST моделью турбулентности для режимов $\mathrm{M}_{\text {вых. }}=0.176(a)$ и $\mathrm{M}_{\text {вых. }}=0.348(b)$

Стоит обратить внимание, что нарастающий пограничный слой на фюзеляже влияет на параметры потока перед входным устройством, что наглядно показывают картины обтекания мотогондолы на рис. 9. С изменением степени дросселирования В3 захватывает большую долю невозмущенного воздушного потока рис. $9, b$ по сравнению с его количеством при большей степени дросселирования рис. 9, $a$, когда втекание потока в В3 определяется взаимодействием мотогондолы с пограничным слоем фюзеляжа. Это явление вносит дополнительную неравномерность входного потока в В3. Потери на входе в В3 составляют $\sigma\left(\mathrm{M}_{\text {вых. }}=0.176\right)=$ 0.999 и $\sigma\left(\mathrm{M}_{\text {вых. }}=0.348\right)=0.996$.

В качестве наглядного примера на рис. 10 и 11 представлены схемы расположения приемников статического давления и распределения обезразмеренного статического давления $P / P_{\text {атм. }}=f\left(X / R_{\mathrm{B} 3}\right)$ по длине В3 и фюзеляжа с использованием вышеуказанных моделей турбулентности и экспериментальных данных на режиме дросселирования, соответствующим числам Маха $\mathrm{M}_{\text {вых. }}=0.176$ и $\mathrm{M}_{\text {вых. }}=0.348$.

На графиках наблюдается выравнивание значения статического давления по длине воздухозаборника при $X / R_{\mathrm{B} 3}=2$, что говорит об отсутствии отрывных зон в поле внутреннего течения.

Как и ранее, во входной части канала В3, рис. 10, расчетные распределения статического давления с $k-\varepsilon$ и SST моделями турбулентности хорошо коррелируют с экспериментальными данными, однако ближе к выходному участку наблюдается отклонение значений статического давления в исследовании с $k$ - $\varepsilon$ моделью турбулентности. На графиках рис. 11 наблюдается резкое изменение значений статического давления при $X / R_{\mathrm{B} 3}=0$, вызванное расположением В3 на фюзеляже. Расчет с использованием SST модели турбулентности достаточно хорошо совпадает с результатами эксперимента и отличие между ними не превышает $3 \%$. Отмеченное отличие может быть вызвано как погрешностями установки модели объекта по оси АДТ и характером взаимодействия мотогондолы с реальным пограничным слоем (в большей степени), образующимся на фюзеляже, так и возможным отличием расчетного обтекания модели в условиях неограниченного потока от условий обтекания в тракте АДТ. 


$$
\text { P/Рaтм }
$$
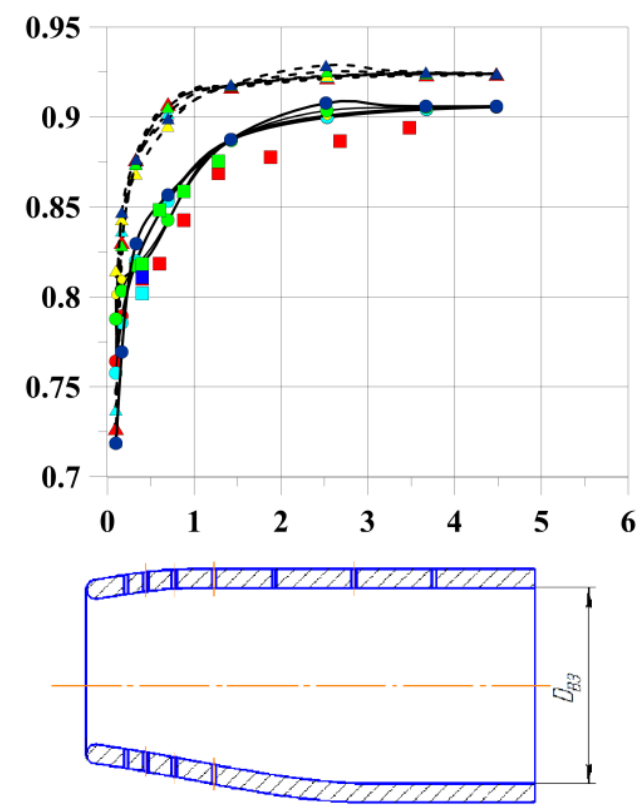

$a$
Р/Paтм
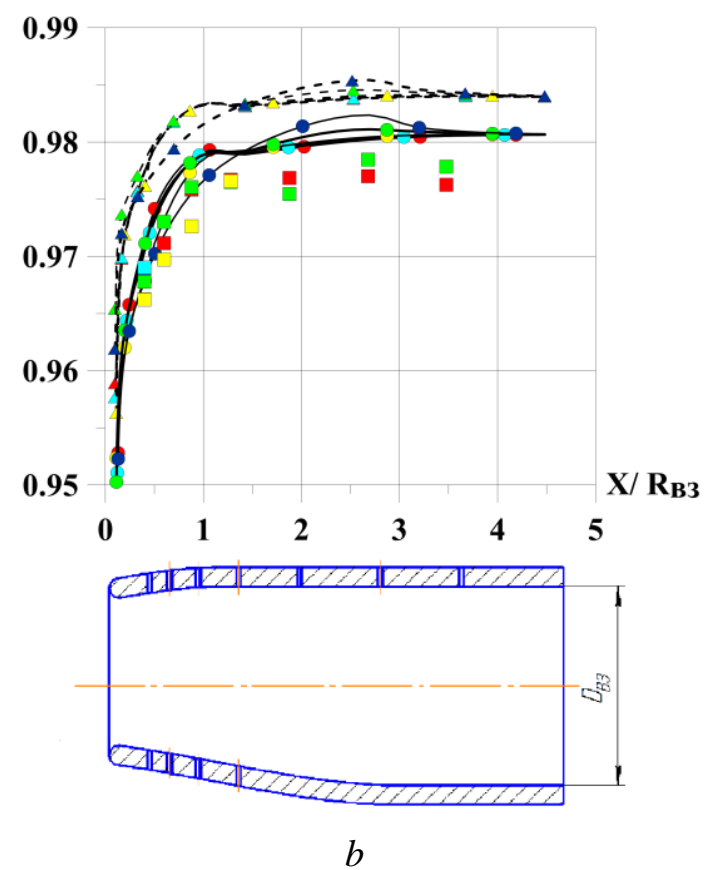

Рис.10 Распределения относительного статического давления $\mathrm{P} / \mathrm{P}_{\text {атм }}$ по длине $\mathrm{B} 3$ для режимов дросселирования с $\mathrm{M}_{\text {вых }}=0.176$ (a) $u \mathrm{M}_{\text {вых }}=0.348(b)$ :

- - эксперимент для лучей I-V соответственно;

- расчет с SST моделью для лучей I-V соответственно;

- расчет с $k$ - $\varepsilon$ моделью для лучей $\mathrm{I}-\mathrm{V}$ соответственно
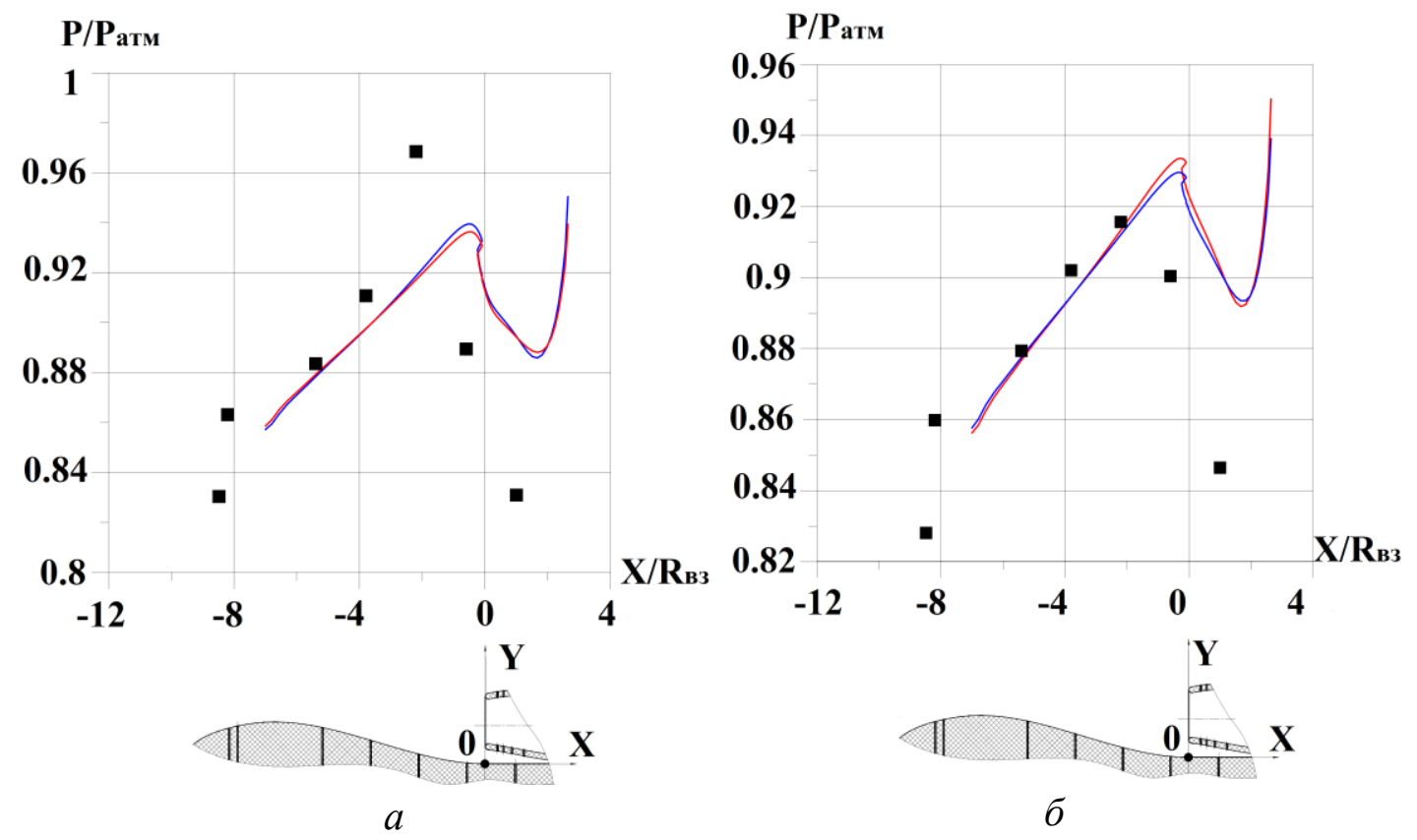

Рис.11. Распределения относительного статического давления $\mathrm{P} / \mathrm{P}_{\text {атм }}$ по длине фюзеляжа для режимов дросселирования $\mathrm{M}_{\text {вых }}=0.176(a)$ и $\mathrm{M}_{\text {вых }}=0.348(b)$

- - эксперимент,

- численное моделирование с SST моделью турбулентности,

- численное моделирование с $k$ - $\varepsilon$ моделью турбулентности 
Потери полного давления в потоке на входе в В3 вызваны его взаимодействием с пограничным слоем, наросшим на фюзеляже. В работе [5] представлены результаты применения синтетических струй для управления течением в переходных каналах и уменьшения неравномерности потока в сечении на входе в двигатель. Поэтому в дальнейших исследованиях обтекания воздухозаборника в компоновке с фюзеляжем предполагается использование синтетических струй на поверхности фюзеляжа перед входом в В3.

\section{5. Заключение}

1. Проведено экспериментальное исследование модели воздухозаборника (В3) в компоновке с фюзеляжем криволинейной геометрической формы в дозвуковой аэродинамической трубе непрерывного действия при моделировании значений скорости $\mathrm{M}_{\text {вых. }}=0.15 \div 0.44$ на выходе В3 на нулевых углах атаки и скольжения и числах Рейнольдса, равных $\operatorname{Re}=1.8 \times 10^{6}$.

Получены экспериментальные характеристики: коэффициент потерь полного давления $\sigma=0.99 \div 0.94$, распределения статического давления по длине фюзеляжа и пространственного воздухозаборника на режимах с дросселированием течения и без.

2. С целью сравнения с данными экспериментов и верификации расчетного метода получены расчетные характеристики В3 с использованием программного пакета ESI - Software, позволяющего рассчитывать пространственные вязкие трехмерные турбулентные течения газа в процессе установления по времени с помощью интегрирования осредненных по Рейнольдсу уравнений Навье-Стокса (RANS). Сравнение результатов экспериментального и численного исследования показало качественную корреляцию результатов, полученных с использованием SST модели турбулентности, с погрешностью менее 3\% по полученным характеристикам.

3. Анализ результатов численного моделирования показал, что:

- $\quad$ с ростом степени дросселирования течения в В3 $\left(\mathrm{M}_{\text {вых }} \geq 0.348\right)$ значительно изменяется распределение полного давления потока на выходе из В3 и, как следствие, наблюдается падение коэффициента полного давления $\sigma$ на $5 \%$;

- дополнительно ухудшение характеристик В3 вызывается захватом образующегося на фюзеляже пограничного слоя, который вносит дополнительные потери в канале В3;

- получены необходимые характеристики ВУ для исследованных условий обтекания в компоновке с фюзеляжем, что позволит в дальнейшем использовать активные методы управления потоком, и, в частности, применение синтетических струй.

\section{Благодарности}

Авторы признательны сотрудникам экспериментального сектора Середину А.В., Макарову Ю.О. и Шкуруку Д.М. за активную помощь в подготовке экспериментальной модели, ее монтаже на стенде и участии в испытаниях.

\section{Литература}

1. Frances Fiorino, "Safety of course", Aviation week and space technology, July 28, 2008, page 70.

2. Jonathan Nash, "Design, construction and calibration of a transonic wind tunnel", Johannesburg: School of Mechanical Engineering, January 31, 2013.

3. ESI GROUP CFD - ACE.

4. Виноградов В.А., Гурылева Н.В., Иванькин М.А., Степанов В.А. “Особенности торможения высокоскоростного потока в конвергентных нерегулируемых воздухозаборниках”, Ученые Записки ЦАГИ, Том XLIII, № 4, 2017.

5. Белова В.Г., Степанов В.А. Многопараметрические расчетные исследования генератора синтетических струй для активного управления течением в переходных каналах. Инженерный журнал: наука и инновации, 2018, № 4, DOI: 10.18698/2308-6033-2018-4-1742. 